\title{
Pelatihan Pembukuan Kelompok Wanita Tani (KWT) Karya Bunda
}

\author{
Nugraeni *1, Indah Susilawati ${ }^{2}$ \\ 1,2Universitas Mercu Buana Yogyakarta; Jalan Wates Km 10 Yogyakarta, 0274-6498212 \\ 1,2Program Studi Akuntansi, Fakultas Ekonomi, Universitas Mercu Buana Yogyakarta \\ e-mail: nugraeni@mercubuana-yogya.ac.id 1 ,indah_nik@yahoo.co.id²
}

\begin{abstract}
The Women Farmers Group (KWT) is a group of mothers in order to advance agriculture, especially the management of agricultural products, economic growth and community welfare (eradicating poverty, overcoming unemployment), social and cultural development. KWT Karya Bunda is located in Patukan, Ambarketawang, Gamping, Sleman Yogyakarta, within 7.5 KM from Mercu Buana University Yogyakarta. This KWT has a strategic location which is close to the Vegetable and Fruit Main Market. This PKM helps the problem of managing KWT, namely bookkeeping and online promotion. The method used is online training and mentoring and promotion. The result of the PKM is an increase in knowledge about preparing financial statements (balance sheets, reports of changes in capital and profit and loss reports) i. So you can find out how many assets and where these assets come from, can arrange cash flow for the future. With online promotion there is an increase in income
\end{abstract}

Keywords: KWT, online promotion, bookkeeping

\begin{abstract}
Abstrak
Kelompok Wanita Tani (KWT) merupakan kumpulan ibu-ibu dalam rangka memajukan pertanian khususnya pengelolaan hasil pertanian, pertumbuhan ekonomi dan kesejahteraan masyarakat (menghapus kemiskinan, mengatasi pengangguran), pengembangan sosial dan budaya. KWT Karya Bunda terletak di Patukan, Ambarketawang, Gamping,Sleman Yogyakarta, berjarak 7,5 KM dari Universitas Mercu Buana Yogyakarta. KWT ini memiliki letak strategis yaitu dekat dengan Pasar Induk Sayur dan Buah. PKM ini membantu permasalahan mengelola KWT,yaitu pembukuan dan promosi online. Metode yang digunakan pelatihan dan pendampingan pembukuan dan promosi online. Hasil dari PKM adalah terjadi peningkatan pengetahuan tentang menyusun laporan keuangan( neraca, laporan perubahan modal dan laporan laba rug)i. Sehingga dapat mengetahui berapa aset dan darimana aset tersebut berasal, dapat menyusun aliran kas untuk masa depan. Dengan promosi online terjadi peningkatkan pendapatan.
\end{abstract}

Kata Kunci: KWT, pemasaran online, pembukuan

\section{PENDAHULUAN}

Kelompok Wanita Tani (KWT) merupakan kumpulan ibu-ibu yang bergerak dalam rangka memajukan pertanian khususnya dalam hal pengelolaan hasil pertanian yang berpotensi pada daerah tersebut. KWT ini juga bagian yang tidak terpisahkan dari kehidupan manusia terutama menyangkut kegiatan sosial dan ekonomi. Pemerintah Daerah Kabupaten Sleman mendukung keberadaan KWT tersebut. Salah satu KWT yang ada di Kabupaten Sleman adalah KWT Karya Bunda yang terletak di Pedukuhan Patukan Desa Ambarketawang Kecamatan Gamping yang berjarak 7,5 KM kearah timur dari Kampus Universitas Mercu Buana Yogyakarta. KWT merupakan kelompok ibu-ibu yang memiliki potensi pertumbuhan ekonomi dan kesejahteraan masyarakat (menghapus kemiskinan, mengatasi pengangguran), pengembangan sosial dan budaya. Di kelurahan Ambarketawang ada 13 pedukuhan dimana masing-masing pedukuhan memiliki satu KWT. KWT Karya Bunda didirikan pada tahun 2012. Saat ini jumlah anggota ada 30 dari masyarakat satu pedukuhan. Pendirian KWT ini bermula dari keinginan ibuibu di pedukuhan Patukan yang mempunyai usaha rumahan membuat makanan, tentang bagaimana pengemasan, bagaimana pemasaran. Juga kesulitan jika ada suatu keluarga yang akan mempunyai hajatan seperti kenduri, mantenan. Saat ini, hampir setiap anggota KWT menanam 
tumbuhan obat dan makanan disekitar pekaranagan. Bagi yang tidak mempunyai pekarangan luas menanam tanaman dalam pot (tabulanpot). Ibu Irian sebagai sesepuh KWT telah menghibahkan pekarangannya seluas 1.000 meter untuk penanaman tumbuhan obat dan sayuran. Hasil panenan dijual ke warga sekitar dan menambah kas KWT. Anggota yang membuat makanan kering sekarang sudah ada tempat untuk menjual yaitu ada toko yang menampung produk makanan dari anggota KWT. Masyarakat sekitar yang mempunyai hajatan, sudah bisa memanfaatkan KWT untuk jasa katering untuk kenduri, ater-ater baik mantenan, aqiqah bayi maupun hajatan lainnya.

Namun, kondisi pengelolaan KWT tersebut belum baik, manajemen pengelolaan masih jauh dari harapan. Untuk pengembangan ada persoalan, yaitu: bagaimana mengelola KWT untuk kedepan. Dari hasil pra research di temukan perihal kebutuhan KWT, yaitu berkaitan dengan pengelolaan manajemen keuangan serta pemasaran secara online. Mitra dalam program kemitraan ini bergerak pada boga atau pengolahan hasil pertanian atau jasa katering. Tempat KWT ini memiliki letak sangat strategis yaitu dekat dengan Pasar Induk Sayur dan Buah di Gamping yang buka 24 jam. Selain itu, diperlukan untuk mendorong pemerataan kesempatan berusaha dan memperoleh manfaat serta mampu menghadapi tantangan perubahan kehidupan lokal, nasional, dan global.

Pengabdian pada masyarakat yang pernah penulis lakukan adalah di kelompok wisata mangrove Jembatan Api-api dan Pantai Pasir Kadilangu di Kabupaten Kulonprogo Yogyakarta (Nugraeni, 2017). Tahun pertama yaitu melalui program Ipteks Bagi Masyarakat (IbM) antara lain pembukuan, pelatihan bahasa Inggris dan pembuatan Web. Tahun kedua melalui Program Kemitraan Masyarakat (PKM) yaitu pembukuan terkomputerisasi, dan pelatihan tour guide bagi pengelola maupun masyarakat anggota kelompok wisata tersebut (Nugraeni, Pelatihan tour guide PKM wisata Mangrove Menyambut New Yogyakarta International airport, 2018). Hasilnya kedua kelompok wisata Jembatan Api-api dan Pantai Pasir Kadilangu mengalami peningkatan yang sangat pesat.

Hasil wawancara dengan beberapa responden di lapangan bahwa KWT sangat membutuhkan bantuan untuk pengembangan dan pembimbingan tentang berbagai hal yang menyangkut manajemen tata kelola dan pemasaran. Hal tersebut menurut Dina, ketua KWT Karya Bunda adalah karena mayoritas anggotanya adalah ibu-ibu rumah tangga yang belum mengerti bagaimana mencatat pembukuan dan bagaimana mempromosikan lewat online. Selama ini pencatatan hanya sederhana sekali, berapa uang dikeluarkan berapa uang didapat, juga promosi hanya dari mulut ke mulut atau masih manual.

Maka beberapa permasalahan yang dihadapi mitra dapat diidentifikasi sebagai berikut:

1. Belum memiliki manajemen keuangan yang baik dan minimnya pengetahuan anggota kelompok terhadap sistem pembukuan tersebut.

2. Kemampuan sumber daya manusia yang masih minim, sampai saat ini KWT tersebut dikelola oleh ibu-ibu rumah tangga.

3. Belum memiliki/lengkapnya media untuk melakukan pemasaran secara online.

\section{METODE}

\section{Pelatihan}

Metode Pelaksanaan dalam program ini terdiri dari empat langkah sebagai berikut:

Pelatihan telah diadakan baik untuk pembukuan bagi UMKM maupun promosi online (Dewi, CD, \& Rizky, 2019). Hal ini dilakukan sebagai modal awal bagi pengelola dan anggota KWT untuk memahami tata kelola KWT yang baik serta memiliki kemampuan menyusun laporan keuangan yang baik dan benar.

2. Pendampingan

Pendampingan diadakan dua kali pada bulan ketiga dan ketujuh pengabdian, hal ini dilakukan setelah pengelola KWT dan masyarakat sekitar memiliki pemahaman manajemen keuangan yang baik serta memiliki kemampuan promosi.

3. Praktek penyusunan 
Praktek pengelolaan terbagi dalam dua kegiatan: (1) Penyusunan laporan keuangan ; dan (2) praktek promosi online.

4. Evaluasi Program

Evalusi dilakukan dengan dua tahap (1) evaluasi kegiatan, pada saat berlangsungan pengabdian dan; (2) evaluasi akhir, pada akhir bulan pengabdian. Evaluasi kegiatan dilakukan setelah kegiatan-kegiatan dilakukan, agar setiap kegiatan dalam program pengabdian memiliki kualitas yang lebih baik. Sementara evaluasi akhir diperlukan untuk melalukan evaluasi menyeluruh terhadap program pengabdian, evaluasi ini dilakukan pada akhir bulan pengabdian dan dilakukan bersama-sama dengan pengelola KWT.

Tabel 1. Masalah dan metode

\begin{tabular}{lllll}
\hline No & Masalah & Metode dan kegiatan & \\
\hline \hline 1 & Belum adanya manajemen keuangan & Pelatihan dan pendampingan & sistem \\
& dan minimnya pengetahuan anggota & manajemen keuangan manual & \\
& KWT terhadap sistem pembukuan & &
\end{tabular}

2. Lemahnya sumber daya manusia

Pelatihan dan Pendampingan Manajemen SDM yang baik, baik untuk pengelola maupun anggota KWT

3. Pengelola belum memiliki kemampuan Pelatihan dan pendampingan promosi pengembangan media online sesuai online kebutuhan

4. Kurangnya program pemasaran dan Promosi secara online

Pelatihan dan pendampingan pelaksanaan marketing online

Sumber: data diolah

\section{HASIL DAN PEMBAHASAN}

\section{Koordinasi dengan pengelola KWT Karya Bunda}

Pada tahap ini telah dilakukan koordinasi dengan pengurus pengelola KWT Karya Bunda Ibu Dina Rakhmawati, S.Si tentang berbagai persiapan yang dibutuhkan dan akan dilakukan selama penyelenggaraan program PKM ini. Hal ini berkaitan dengan berbagai pelatihan yang akan dilakukan program PKM yaitu : pelatihan pembukuan dan pelatihan promosi online. Antara lain disepakati tentang waktu dilakukan pelatihan, tempat pelatihan serta peserta pelatihan. Program telah terkoordinasikan dengan pengurus sebagai operator dan fasilitator kelompok.

\section{Pelatihan}

Pada tahap ini telah dilakukan pelatihan untuk anggota kelompok pengelola KWT Karya Bunda. Pelatihan dua macam yaitu pelatihan pembukuan secara manual dan pelatihan promosi secara online. Pelatihan pembukuan secara manual, dengan instruktur Nugraeni, SE, M.Sc dan dibantu mahasiswa program studi akuntansi yaitu Anggi Pratiwi. Pelatihan pembukuan diikuti oleh pengelola dan semua anggota KWT Karya Bunda. Peserta diberikan pelatihan tentang bagaimana menyusun laporan keuangan secara manual untuk UMKM pemula yang terdiri dari Neraca, Laporan Laba rugi serta Laporan Perubahan Modal. Selain mendapatkan teori juga dilengkapi dengan praktek menyusun laporan keuangan tersebut. Pelatihan promosi online dengan instruktur Indah Susilawati, ST, M.Eng dengan dibantu mahasiswa program studi Tekhnik Informatika yaitu Andi Nur Sodik. Selain dengan teori juga dilengkapi dengan praktek promosi lewat online. 


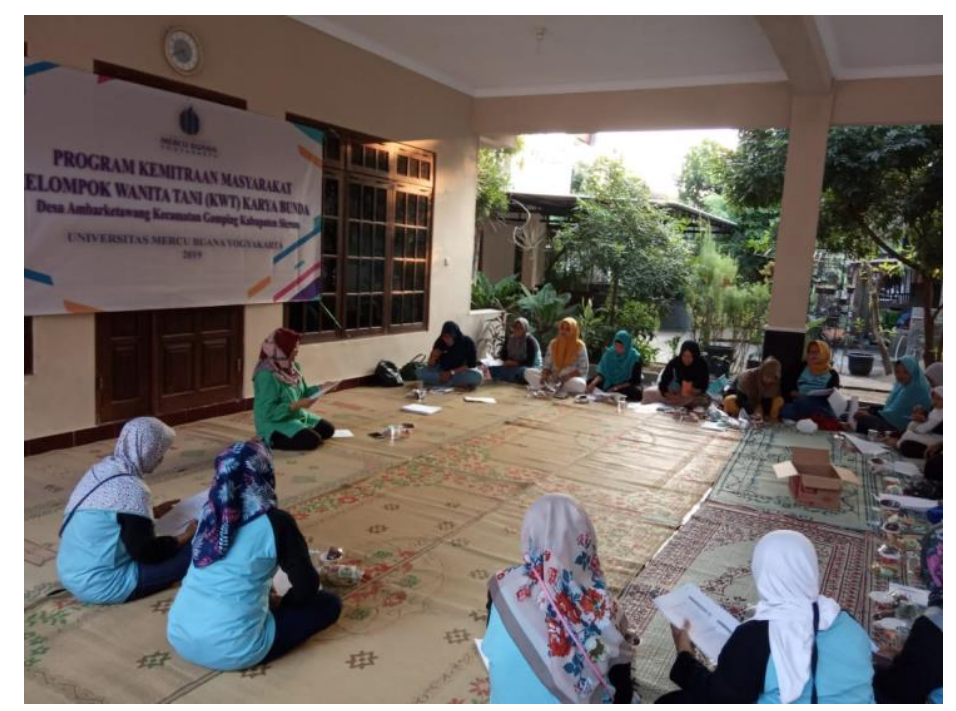

Gambar. 1. Pelatihan pembukuan KWT Karya Bunda

\section{Penyerahan bantuan}

Untuk mendukung kinerja pengelolaan KWT Karya Bunda dari program PKM Universitas Mercu Buana Yogyakarta, memberikan bantuan berupa dana untuk pengadaan bibit sayuran dan buah. Sebanyak 100 unit bibit sayur sawi hijau, cabe, dan bayam. Kemudian tanaman buah mangga, belimbing madu, jeruk dan rambutan masing-masing sebanyak 50 unit.

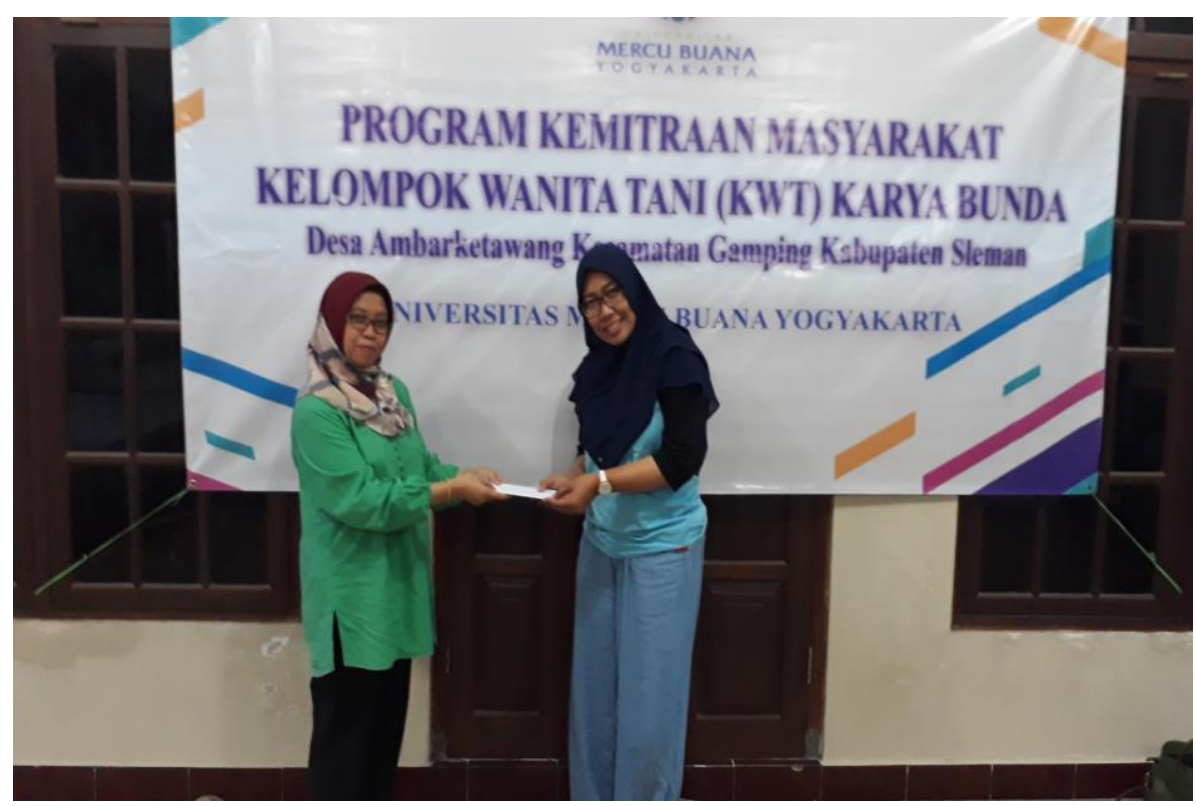

Gambar 1. Penyerahan bantuan 


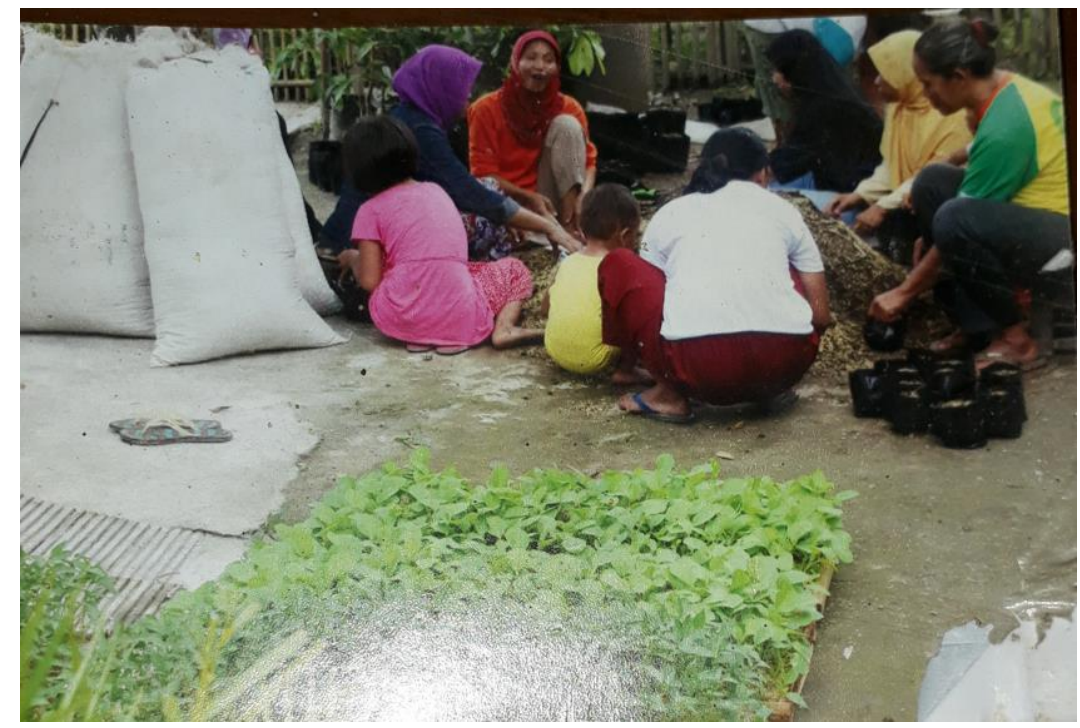

Gambar. 2. Anggota menanam tanaman sayuran

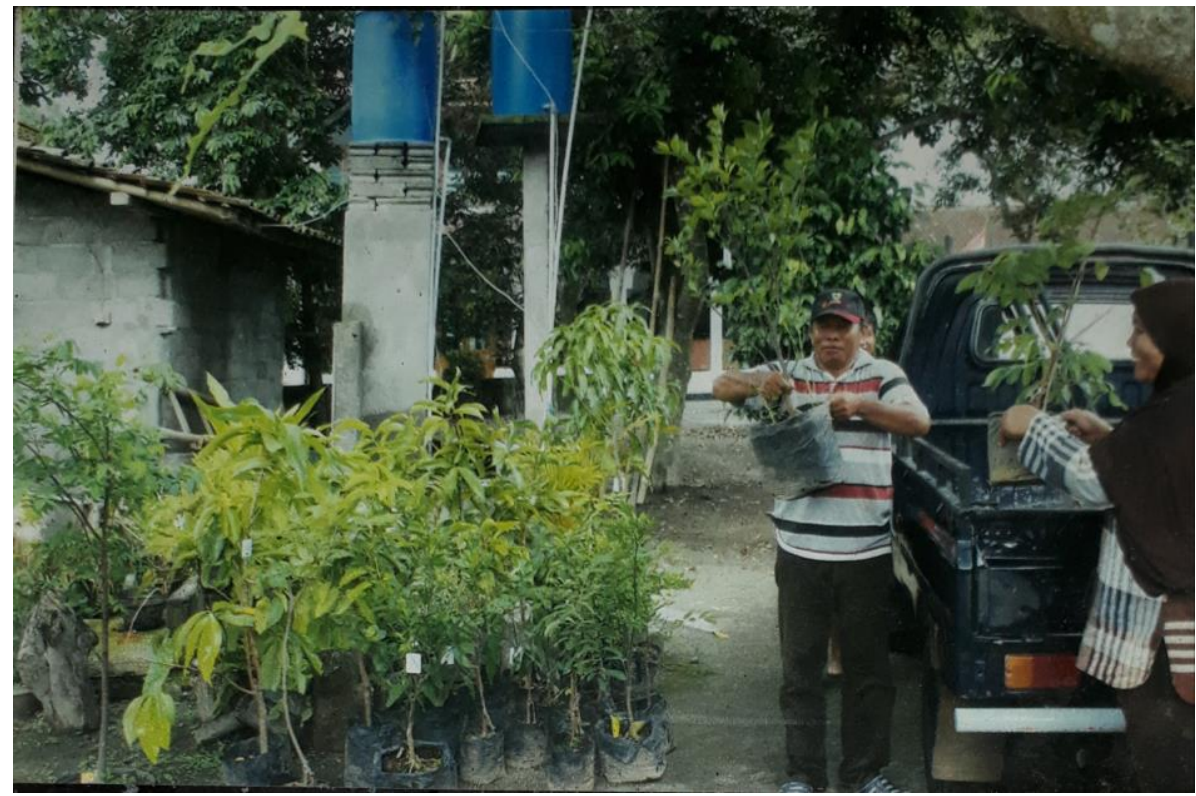

Gambar 3. Distribusi tanaman buah

\section{Dampak}

Setelah dilaksanakan pelatihan dan pendampingan pembukuan dan promosi online, diperoleh peningkatan dari segi pengetahuan dan pendapatan kelompok wanita tani (KWT) Karya Bunda. Pengurus dan anggota dapat menyusun laporan keuangan sehingga dapat mengetahui posisi harta dan darimana harta berasal, dapat mengetahui laba rugi usaha, dapat memprediksi aliran kas masa depan serta dapat memasarkan produknya secara online.

\section{KESIMPULAN}

1. Sebagai pengelola KWT, pembukuan sangat penting, agar pengelola maupun anggota dapat mengetahui kemajuan usaha.

2. Kemampuan promosi secara online juga perlu. Hal ini untuk menghadapi kemajuan tekhnologi yang serba online.

3. Perlu disiapkan SDM yang bisa menangani tentang pembukuan dan promosi secara online, karena pengelola yang ada sudah terbagi waktunya untuk pengolahan atau produksi.

\section{SARAN}


Saran untuk pengabdian pada masyarakat selanjutnya :

1. Untuk pembukuan menggunakan program akuntansi terkomputerisasi tidak hanya manual.

2. Untuk pemasaran online pendampingan lebih intensif.

\section{UCAPAN TERIMA KASIH}

Penulis mengucapkan terima kasih kepada Universitas Mercu Buana Yogyakarta dan LPPM yang telah memberi dukungan financial terhadap pengabdian ini.

\section{DAFTAR PUSTAKA}

Budi Santoso, Tri Handoyo, Ummi Solikhak, (2014), IbM Usaha Kripik Salak di Kelompok Wanita Mandiri Taman Jaya Desa Taman Ayu Kabupaten Lumajang, Universitas Jember.

Dewi, RS., Anita,OCD., \& Rizky,N.,( 2019), Perancangan dan Implementasi sistem E-Commerce Pada UMKM Batik di Kabupaten Jombang, Dinamisia, Vol 3 No 1, 36-43

Hamdi Khairil., Dirris Yadewani, ( 2019), Pengembangan Usaha Kuliner Home Industri Sebagai Peluang Kaum Perempuan Menuju Indonesia Kreatif, Dinamisia, Vol 3 Special Issue, 110116

Hasaniatun Alfingah, 2017, Pemberdayaan Ekonomi Kelompok Wanita Tani (KWT) Ngudi Makmur Dusun Nayan Desa Maguwoharjo Kecamatan Depok Sleman, Skripsi

Kieso, Weygandt, Accounting Principles, Edisi IFRS, John-Wiley \& Sons Publishing 2010

Latifa, S., Surtinah, \& Rini, N, ( 2019), Pemberdayaan Ibu Rumah Tangga Melalui Pelatihan Membuat Hantaran Pernikahan Melayu Motif Satwa, Dinamisia, Vol 2 No 2, 205-210

Mm, S. T., Industri, J. T., \& Industri, F. T. (2014). IbM Usaha Budidaya dan Pengolahan Aneka Kuliner Lele di Kecamatan Gedeg Anggota 2 : Nugroho Priyo Negoro SE ST MT, 1-32.

Nugraeni, N., \& Setyawan, A. H. (2017). I BM WISATA MANGROVE JEMBATAN API-API DAN PANTAI PASIR KADILANGU , MANDIRI DAN SEJAHTERA, Proceeding SNaPP 2017, Unisba Bandung,160-170.

Nugraeni, \& Setyawan, A.H. (2017), Pelatihan Tour guide dan pembukuan untuk peningkatan omzet wisata mangrove, SEMNAS PPM UAD, 176-183.

Yermadona, H., Earnestly, F., Afrijon., Suryani, S., 2019. Pemberdayaan Ibu-ibu PKK Nagari Sikucur Barat Melalui Produksi Virgin Coconut Oil (VCO). Dinamisia. Vol 3. Special Issue, 171-190

Taman, M., Desa, J., Ayu, T., \& Lumajang, K. (2014). ( IbM ), (20126004). 